\title{
nutrients
}

ISSN 2072-6643

www.mdpi.com/journal/nutrients

Article

\section{Assessing Eating Disorder Risk: The Pivotal Role of Achievement Anxiety, Depression and Female Gender in Non-Clinical Samples}

\author{
Konstantinos C. Fragkos ${ }^{1, *}$ and Christos C. Frangos ${ }^{2}$ \\ 1 Centre for Gastroenterology and Nutrition, Division of Medicine, University College London, \\ Rockefeller Building, 21 University Street, London, WC1E 6DE, UK \\ 2 Department of Business Administration, Technological Educational Institute (TEI) of Athens, \\ Agiou Spyridonos Street, Egaleo 12210, Athens, Greece; E-Mail: cfragos@teiath.gr
}

* Author to whom correspondence should be addressed; E-Mail: constantinos.frangos.09@ucl.ac.uk; Tel.: +44-7960-340489; Fax: +44-2032-876102.

Received: 12 December 2012; in revised form: 18 January 2013 / Accepted: 22 February 2013 / Published: 12 March 2013

\begin{abstract}
The objective of the present study was to assess factors predicting eating disorder risk in a sample of undergraduate students. A structured questionnaire was employed on a random sample $(n=1865)$ consisting of the following sections: demographics, SCOFF (Sick, Control, One stone, Fat, Food) questionnaire for screening eating disorders and the Achievement Anxiety Test and the Depression, Anxiety and Stress Scale. The students at risk for eating disorders (SCOFF score $\geq 2$ ) were 39.7\%. Eating disorder risk was more frequent in females, students with divorced parents, students who lived alone, students who were seeking a romantic relationship or were married, students who were at a post-secondary vocational institute/college (private-public) educational level and who were more likely to have marks under merit level. Also, the mean scores for the psychological factors of depression, stress and anxiety were higher in students with eating disorder risk. A logistic regression model was produced depicting that depression, stress, female gender, being married and searching for a romantic relationship were risk factors of having an eating disorder risk. The suggested psychological model examined with structural equation modelling signified the role of academic anxiety as an immediate precursor of general anxiety. Hence, college populations in Greece need organized infrastructures of nutrition health services and campaigns to assist in reducing the risk of eating disorders.
\end{abstract}


Keywords: eating disorders risk; female gender; romantic relationships; logistic regression; structural equation modelling

\section{Introduction}

The term "eating disorder" refers to a persistent and severe disturbance of eating habits that results in impaired physical health or psychosocial functioning [1]. Anorexia nervosa and bulimia nervosa are the best characterized of the eating disorders [2]. Eating disorders and obesity may coexist, although in clinical practice, most people with an eating disorder have normal or low body weight. Eating disorders are among the potentially lethal psychiatric illnesses and are predominately represented by a mental effect of preoccupation with body weight, shape and diet [3,4]. They frequently occur with other psychiatric disorders, such as depression, substance abuse and anxiety disorders [5]. Although their exact cause is unknown, it is believed that a combination of biological, psychological and/or environmental abnormalities contribute to their development $[1,6]$.

Assessing aetiology for eating disorders requires considering multifactorial theories from psychiatry and college health. Initially, the core assumption of eating disorders' aetiology and maintenance is a dysfunctional system for evaluating self-worth, whereas most people evaluate themselves on the basis of their perceived performance in a variety of domains of life, people with eating disorders judge themselves largely or even exclusively, in terms of their eating habits, shape or weight (and often all three) and their ability to control them [7]. These distinctive and highly characteristic, behavioural and attitudinal features are prominent and well-recognised, as is the dysfunctional system for evaluating self-worth [8]. Jacobi et al. [9] classification for the aetiopathology of eating disorders offers a reasonable starting point for assessment of putative risk factors, with the ability to adjust their investigation to certain theories. Additionally, college health scholarship commonly regards the transition to college as a high-risk period for the development of eating disorders, given the notably high rates of dieting, body dissatisfaction and disordered eating among college students, the association between stress and eating disorder symptoms and the typical onset of bulimia nervosa in late adolescence and early adulthood and anorexia nervosa in mid-late adolescence [10-13]. Prevalence estimates of current eating disorders among college students range from $8 \%$ to $17 \%$ [1].

In college students' samples, there is an increasing presence of academic related stress and anxiety. There are now certain studies, along with many case reports or newspaper articles, which report of students (mainly female) who neglect their eating patterns, because of increased academic pressure [14]. Psychological factors have been readily associated with eating disorders, most notably with depression, stress and anxiety [9]. Standard factors that are also present in eating disorders involve female gender, family factors and socio-economic factors [4,6,15]. Female gender has been associated very strongly with the presence of eating disorders [16]. Family dysfunction with a negative intra-family climate has been shown to affect negatively the presence of eating disorders [17,18]. Apart from a negative family status, the status of being in a relationship has been shown to possibly affect the presence of eating disorders [19]. Also, considering that unemployment has been associated 
many times with other psychiatric disorders, this has not been explored in association with eating disorders $[20,21]$.

These studies point out the significance of addressing eating pathology in college populations, particularly considering the many channels-residential life, academics, extracurricular activities, social networks and health services - by which students can be reached [1]. Understanding populations who are not receiving clinical care is important, as early detection and treatment of eating disorders greatly increases the chances of full recovery. A more detailed picture of how these variables relate to eating disorder risk can help inform efforts to target or tailor intervention strategies on campuses [15,22].

In Greek cohort studies, observations are largely similar. There isn't an extensive literature in the field yet; however, some conclusions can be drawn [8,23-36]. Studies on adolescents have reproduced international findings where false body image and female gender are positive predictors of eating disorders $[24,27,34]$. There have been a couple of studies on college student samples, which showed similar results with respect to gender and pointed out the role of anxiety traits $[30,32]$. However, samples involve specific faculty departments or specific groups. There isn't a conclusive image of students' eating disorder risk after adolescents have finished high school in Greece.

Hence, it is important to understand how eating disorder risk varies across student characteristics, such as sex, academic level, family status and interpersonal relationships, as well as employment status. Thus, in this study, we addressed these knowledge gaps using a randomly selected sample of students from post-secondary institutions and public universities in Athens, Greece. First, we estimated the prevalence of eating disorder risk symptoms across subgroups defined by sex, academic level, employment status and family factors, using a standardized instrument. We hypothesized that the prevalence of eating disorder risk symptoms would be higher among women, as in previous studies, whereas we did not have a clear expectation regarding differences by academic level, family or employment status (due to the sparse literature on eating disorder risk associated with these factors in college populations). Second, we estimated the extent to which eating disorder risk symptoms co-occurred with depressive, anxiety and stress symptoms, with particular emphasis on academic stress. We hypothesized that eating disorder risk symptoms would be positively correlated with depression, anxiety, stress and academic related anxiety. Finally, we examined a psychological model under which eating disorder risk could be caused by the presence of these psychological traits.

\section{Methodology}

\subsection{Participants}

The cross-sectional sample survey was conducted between January 2010 and January 2011 among a random sample of students who had graduated from at least high school. This involves post-secondary vocational school students, undergraduate or postgraduate students, drawn randomly from public or private educational institutions in Athens. In Greece, higher educational institutions are of two categories: technological educational institutes (TEI) and higher educational institutes (in Greek, AEI). TEIs were previously polytechnics, now delivering university level education mostly in the technical fields; AEI refers to what is commonly considered as universities. Sampling was based 
on the techniques suggested by Bartlett et al. [37]. Questionnaires were distributed and completed with face-to-face interviews. The sample size chosen was three-times the allowed sample size for representativeness (suggested sample size for 95\% confidence level, tolerated margin error 3\% and response rate over $80 \%$ is 683) [37]. Hence, 1978 questionnaires were distributed to these institutions; 113 were excluded due to incomplete answers. Hence, the final sample size analyzed was 1865 . The sample consisted of $45.5 \%$ males and $54.5 \%$ females, and mean age was 21.2 years. Age distribution is shown in Table 1, along with other demographics regarding family, academic and employment statuses. The present study was approved by the Institutional Board of the organizing institution (TEI of Athens) and was executed following the principles of confidentiality, anonymity and informed consent, as outlined by the Declaration of Helsinki and its subsequent revisions.

Table 1. Sample characteristics.

\begin{tabular}{lll}
\hline Variable & Frequency & \% \\
\hline Age & & \\
\hline $16 \leq$ age $<18$ & 265 & 14.2 \\
$18 \leq$ age $<22$ & 1007 & 54.0 \\
$22 \leq$ age $<26$ & 389 & 20.9 \\
$26 \leq$ age & 110 & 10.7 \\
NA & 4 & 0.2 \\
\hline Family status & & \\
Do your parents live together? & & \\
Yes & 1469 & 78.8 \\
No & 360 & 19.3 \\
NA & 36 & 1.9 \\
Are your parents divorced? & & \\
Yes & 343 & 18.4 \\
No & 1270 & 68.1 \\
NA & 252 & 13.5 \\
Whom do you live with? & & \\
My parents & 1114 & 59.7 \\
Alone, because I work and I am financially independent. & 231 & 12.4 \\
Alone, because I study in a different town from my parents. & 407 & 21.8 \\
Alone, because I study and I want to be independent of control. & 108 & 5.8 \\
NA & 5 & 0.3 \\
Personal family status & & \\
Single & 1325 & 71.0 \\
Married & 79 & 4.2 \\
Divorced & 24 & 1.3 \\
Permanent relation, but unmarried & 227 & 12.2 \\
Engaged & 48 & 2.6 \\
Seeking romantic relationship & 153 & 8.2 \\
NA & 9 & 0.5 \\
\hline
\end{tabular}


Table 1. Cont.

\begin{tabular}{|c|c|c|}
\hline \multicolumn{3}{|l|}{ Academic status } \\
\hline \multicolumn{3}{|l|}{ Current educational institutional level } \\
\hline Post-secondary vocational institute/college (private-public) & 304 & 16.3 \\
\hline Higher educational institution-TEI & 793 & 42.5 \\
\hline Higher educational institution-AEI & 509 & 27.3 \\
\hline Postgraduate studies & 106 & 5.7 \\
\hline NA & 153 & 8.2 \\
\hline \multicolumn{3}{|l|}{ Highest educational degree attained till today } \\
\hline GCSE/A-levels & 1477 & 79.2 \\
\hline $\begin{array}{l}\text { Graduation certificate from post-secondary } \\
\text { vocational institute/college (private-public) }\end{array}$ & 56 & 3.0 \\
\hline Bachelors & 212 & 11.4 \\
\hline Postgraduate degree & 46 & 2.5 \\
\hline NA & 74 & 4.0 \\
\hline \multicolumn{3}{|c|}{$\begin{array}{l}\text { If you are a freshman, what was your mark average during your last year of high-school } \\
\text { or during A-levels? (Marks range from } 0=\text { fail to } 20=\text { distinction) }\end{array}$} \\
\hline $\operatorname{mark} \leq 10$ & 56 & 3.0 \\
\hline $10.1 \leq$ mark $\leq 14$ & 380 & 20.4 \\
\hline $14.1 \leq$ mark $\leq 18$ & 688 & 36.9 \\
\hline $18.1 \leq$ mark $\leq 20$ & 114 & 6.1 \\
\hline NA & 627 & 33.6 \\
\hline \multicolumn{3}{|l|}{ Mark average during previous term } \\
\hline Fail & 83 & 4.5 \\
\hline Pass & 364 & 19.5 \\
\hline Merit & 544 & 29.2 \\
\hline Distinction & 170 & 9.1 \\
\hline NA & 704 & 37.7 \\
\hline \multicolumn{3}{|l|}{ Employment status } \\
\hline \multicolumn{3}{|l|}{ Do you work? } \\
\hline Yes & 856 & 45.9 \\
\hline No & 954 & 51.2 \\
\hline NA & 55 & 2.9 \\
\hline \multicolumn{3}{|l|}{ If yes, are you full-time or part-time? } \\
\hline Full time & 385 & 20.6 \\
\hline Part time & 529 & 28.4 \\
\hline NA & 951 & 51.0 \\
\hline
\end{tabular}

NA: not available.

\subsection{Measures}

Demographics: This section consisted of 12 items with questions on age, gender, family, academic and employment statuses. Results are shown in Table 1.

SCOFF: The SCOFF questionnaire is a simple 5-question screening tool for eating disorders. Its acronym is derived from initial wordings in its 5 items [38]. Answers to items are yes or no; an answer of yes to 2 or more of these questions indicates a likely case of anorexia or bulimia [39]. 
These questions are easy to recall and can guide practitioners in identifying who is at risk for such disorders. Initial testing in the United Kingdom revealed that a threshold of 2 or more positive answers out of 5 gave a $100 \%$ sensitivity (95\% CI $96.9 \%-100 \%)$ and an $87.5 \%$ specificity (95\% CI 79.2\%-93.4\%) [39,40]. It has previously been validated in Greek students [41,42]. It is a reliable and valid screening tool that has been translated into various languages $[43,44]$. Even though the cut-off point is the same, sensitivity and specificity values are different in these studies.

Depression Anxiety Stress Scale: The Depression Anxiety Stress Scale (DASS) assesses the experience of 42 negative emotional symptoms over the previous week on a 4-point Likert scale, ranging from 0 (does not apply to me) to 3 (applied to me very much) [45]. The DASS was originally developed and validated in Australia, but it has also been validated and translated for use in other countries, such as in the United Kingdom, Malaysia, Arabic countries and Spain among others [46]. The DASS has three sub-scales, namely depression, anxiety and stress subscale, each consisting of 14 items.

Although DASS has been validated in previous Greek studies [47], its psychometric properties are still unclear especially among university students. Thus, it was necessary to perform exploratory factor analysis (EFA) to examine the underlying structure of the scale among our sample of Greek university students. We performed EFA with principal component analysis. Our analysis recognized three factors explaining $46.7 \%$ of the total variance. These factors were very similar to the item composition of DASS subscales commonly described, with minor differences in items loading in each subscale and certain items having to be dropped. Results are shown in the Appendix. Because of these differences in items, these factors are represented by the factor scores based on EFA, rather than the sum of items in each subscale. Higher values in each score indicate a higher intensity of the condition. Internal consistency of each factor was very high as well (Depression: Cronbach's alpha $=0.937,19$ items; Anxiety: Cronbach's alpha $=0.870,12$ items; Stress: Cronbach's alpha $=0.861,9$ items).

Achievement Anxiety Test (AAT): Alpert and Haber [48] designed the AAT to measure facilitating and debilitating test anxiety. The facilitating scale assesses anxiety as a motivator for academic performance and the debilitating scale assesses the degree to which anxiety interferes with academic performance. The whole scale has 19 items. Previous literature indicates satisfactory test-retest reliability, while both facilitating and debilitating anxiety scores were shown to be significant predictors of grade point averages [49]. In the present study, each scale's Cronbach's alpha was 0.734 and 0.595 respectively, indicating satisfactory internal consistency.

\subsection{Statistical Analysis}

Demographic information was presented with frequencies and percentages. Univariate analyses were done to examine the factors of the questionnaire associated with risk of eating disorders. Chi-square values or independent sample $t$-tests, degrees of freedom and levels of significance are reported. The effects of depression, achievement anxiety in test and general anxiety, as well as stress were tested as precursors of eating disorder risk using path analysis modelling, wherein the model fit was examined, as well as the significance of the direct and indirect effects. The following indicators were used to assess the goodness of fit of the models: Comparative Fit Index and Root Mean Square Error of Approximation. The chi-square statistic was used for the structural invariance tests to determine significant effect modifiers. The maximum likelihood estimation method for structural 
equation modelling was used to test the conceptual model, examining the relationships among latent variables [50]. Finally, we performed stepwise logistic regression with the presence of eating disorder risk as the dependent variable and independent variables several demographic and psychological variables. In all calculations, $p$-values under 0.05 were considered significant, unless otherwise stated. All figures and graphs were produced with PASW 18.0 and AMOS 16.0.

\section{Results}

\subsection{Eating Disorders Risk}

The students at risk for eating disorders were 39.7\%. Univariate analyses showed that factors associated with the disease at the 5\% level were gender, whom they lived with, personal family status, current educational institutional level, depression, anxiety, stress and debilitating test anxiety. Borderline significance (attained at 10\% level of significance) was attained with variables the following: whether parents were divorced, average mark during previous term and facilitating test anxiety (Table 2).

Table 2. Univariate analyses of eating disorder risk with other variables.

\begin{tabular}{|c|c|c|c|}
\hline \multirow{2}{*}{ Variables } & \multicolumn{2}{|c|}{ Eating disorder risk $(\mathrm{SCOFF} \geq 2)$} & \multirow{2}{*}{ Test result } \\
\hline & No & Yes & \\
\hline Categorical variables & $n(\%)$ & $n(\%)$ & Chi-square tests \\
\hline \multicolumn{4}{|l|}{ Demographic characteristics } \\
\hline \multicolumn{4}{|l|}{ Gender } \\
\hline Male & $561(50.0 \%)$ & $288(38.9 \%)$ & \multirow{2}{*}{$\begin{array}{c}\chi^{2}=22.134, \mathrm{df}=1, p<0.0001 \\
\text { or }=1.57(95 \% \text { CI } 1.30-1.90)\end{array}$} \\
\hline Female & $562(50.0 \%)$ & $453(61.1 \%)$ & \\
\hline \multicolumn{4}{|l|}{ Age } \\
\hline $16 \leq$ age $<18$ & $143(12.8 \%)$ & $122(16.5 \%)$ & \multirow{4}{*}{$\chi^{2}=9.185, \mathrm{df}=6, p=0.163$} \\
\hline $18 \leq$ age $<22$ & $631(56.3 \%)$ & $376(50.9 \%)$ & \\
\hline $22 \leq$ age $<26$ & $230(20.5 \%)$ & $158(21.4 \%)$ & \\
\hline $26 \leq$ age & $117(10.4 \%)$ & $8343(11.2 \%)$ & \\
\hline \multicolumn{4}{|l|}{ Family factors } \\
\hline \multicolumn{4}{|l|}{ Do your parents live together? } \\
\hline No & $204(18.5 \%)$ & $156(21.5 \%)$ & \multirow{2}{*}{$\begin{array}{c}\chi^{2}=2.376, \mathrm{df}=1, p=0.123 \\
\mathrm{OR}=0.83(95 \% \text { CI } 0.66-1.05)\end{array}$} \\
\hline Yes & $897(81.5 \%)$ & $571(78.5 \%)$ & \\
\hline \multicolumn{4}{|l|}{ Are your parents divorced? } \\
\hline No & $767(80.1 \%)$ & $502(76.6 \%)$ & \multirow{2}{*}{$\begin{aligned} \chi^{2} & =2.852, \mathrm{df}=1, p=0.09 \\
\mathrm{OR} & =1.23(95 \% \text { CI } 0.97-1.57)\end{aligned}$} \\
\hline Yes & $190(19.9 \%)$ & $153(23.4 \%)$ & \\
\hline \multicolumn{4}{|l|}{ Whom do you live with? } \\
\hline My parents & $694(61.9 \%)$ & $419(56.7 \%)$ & \multirow{4}{*}{$\chi^{2}=11.262, \mathrm{df}=3, p=0.0104$} \\
\hline $\begin{array}{l}\text { Alone, because I work and I am } \\
\text { financially independent }\end{array}$ & $135(12.0 \%)$ & $96(13.0 \%)$ & \\
\hline $\begin{array}{l}\text { Alone, because I study in a different town } \\
\text { from my parents }\end{array}$ & $242(21.6 \%)$ & $165(22.4 \%)$ & \\
\hline $\begin{array}{l}\text { Alone, because I study and I want to be } \\
\text { independent of control }\end{array}$ & $50(4.5 \%)$ & $58(7.9 \%)$ & \\
\hline
\end{tabular}


Table 2. Cont.

\begin{tabular}{|c|c|c|c|}
\hline \multicolumn{4}{|l|}{ Personal Family Status } \\
\hline Single & $828(74.1 \%)$ & $496(67.2 \%)$ & \multirow{6}{*}{$\chi^{2}=30.728, \mathrm{df}=5, p<0.0001$} \\
\hline Married & $28(2.5 \%)$ & $51(6.9 \%)$ & \\
\hline Divorced & $17(1.5 \%)$ & $7(0.9 \%)$ & \\
\hline Permanent relation, but unmarried & $140(12.5 \%)$ & $87(11.8 \%)$ & \\
\hline Engaged & $26(2.4 \%)$ & $22(3.0 \%)$ & \\
\hline Seeking romantic relationship & $78(7.0 \%)$ & $75(10.2 \%)$ & \\
\hline \multicolumn{4}{|l|}{ Academic factors } \\
\hline \multicolumn{4}{|l|}{ Current educational institutional level } \\
\hline $\begin{array}{l}\text { Post secondary vocational institute/college } \\
\text { (private-public) }\end{array}$ & $157(15.2 \%)$ & $147(21.6 \%)$ & \multirow{4}{*}{$\chi^{2}=14.541, \mathrm{df}=3, p=0.002$} \\
\hline Higher education institution-TEI & $508(49.3 \%)$ & $285(41.9 \%)$ & \\
\hline Higher education institution-AEI & $305(29.6 \%)$ & $203(29.9 \%)$ & \\
\hline Postgraduate studies & $61(5.9 \%)$ & $45(6.6 \%)$ & \\
\hline \multicolumn{4}{|l|}{ Highest educational degree attained till today } \\
\hline GCSE/A-levels & $902(83.6 \%)$ & $574(80.5 \%)$ & \multirow{4}{*}{$\chi^{2}=3.432, \mathrm{df}=3, p=0.330$} \\
\hline $\begin{array}{l}\text { Graduation certificate from post secondary } \\
\text { vocational institute/college (Private-Public) }\end{array}$ & $32(3.0 \%)$ & $24(3.3 \%)$ & \\
\hline Bachelors & $116(10.8 \%)$ & $96(13.5 \%)$ & \\
\hline Postgraduate degree & $27(2.6 \%)$ & $19(2.7 \%)$ & \\
\hline \multicolumn{4}{|c|}{ If you are a freshman, what was your average mark during your last year at high-school or during A-levels? } \\
\hline $\operatorname{mark} \leq 10$ & $35(4.8 \%)$ & $21(4.0 \%)$ & \multirow{4}{*}{$\chi^{2}=4.388, \mathrm{df}=5, p=0.495$} \\
\hline $10.1 \leq \operatorname{mark} \leq 14$ & $217(30.0 \%)$ & $163(31.6 \%)$ & \\
\hline $14.1 \leq \operatorname{mark} \leq 18$ & $412(57.1 \%)$ & $276(53.5 \%)$ & \\
\hline $18.1 \leq \operatorname{mark} \leq 20$ & $58(8.1 \%)$ & $56(10.9 \%)$ & \\
\hline \multicolumn{4}{|l|}{ Average mark during previous term } \\
\hline Fail & $40(6.0 \%)$ & $43(8.8 \%)$ & \multirow{4}{*}{$\chi^{2}=6.553, \mathrm{df}=3, p=0.088$} \\
\hline Pass & $199(29.8 \%)$ & $165(33.5 \%)$ & \\
\hline Merit & $330(49.4 \%)$ & $213(43.3 \%)$ & \\
\hline Distinction & $99(14.8 \%)$ & $71(14.4 \%)$ & \\
\hline \multicolumn{4}{|l|}{ Employment status } \\
\hline \multicolumn{4}{|l|}{ Do you work? } \\
\hline No & $557(51.5 \%)$ & $397(54.6 \%)$ & $\chi^{2}=1.708, \mathrm{df}=1, p=0.191$ \\
\hline Yes & $525(48.5 \%)$ & $330(45.4 \%)$ & $\mathrm{OR}=0.88(95 \%$ CI $0.73-1.07)$ \\
\hline \multicolumn{4}{|l|}{ If yes, are you full time or part time? } \\
\hline Full-time & $228(41.6 \%)$ & $157(43.0 \%)$ & $\chi^{2}=0.178, \mathrm{df}=1, p=0.673$ \\
\hline Part-time & $320(58.4 \%)$ & $208(57.0 \%)$ & $\mathrm{OR}=0.94(95 \%$ CI $0.72-1.23)$ \\
\hline
\end{tabular}


Table 2. Cont.

\begin{tabular}{|c|c|c|c|}
\hline Continuous variables & Mean \pm SE & Mean \pm SE & $t$-Tests \\
\hline Depression & $-0.275 \pm 0.026$ & $0.404 \pm 0.040$ & $\begin{array}{l}t=14.868, \mathrm{df}=1796, p<0.0001 \\
\text { Mean difference }(\text { Yes-No })=0.679\end{array}$ \\
\hline Anxiety & $-0.176 \pm 0.031$ & $0.265 \pm 0.035$ & $\begin{array}{c}t=9.336, \mathrm{df}=1796, p<0.0001 \\
\text { Mean difference }(\text { Yes-No })=0.441\end{array}$ \\
\hline Stress & $-0.211 \pm 0.028$ & $0.313 \pm 0.039$ & $\begin{array}{l}t=11.250, \mathrm{df}=1796, p<0.0001 \\
\text { Mean difference }(\text { Yes-No })=0.524\end{array}$ \\
\hline Debilitating achievement anxiety & $32.22 \pm 0.20$ & $30.29 \pm 0.21$ & $\begin{array}{l}t=-6.509, \mathrm{df}=1860, p<0.0001 \\
\text { Mean difference }(\text { Yes-No })=-1.93\end{array}$ \\
\hline Facilitating achievement anxiety & $27.55 \pm 0.15$ & $27.12 \pm 0.19$ & $\begin{array}{c}t=-1.750, \mathrm{df}=1861, p=0.08 \\
\text { Mean difference }(\text { Yes-No })=-0.43\end{array}$ \\
\hline
\end{tabular}

OR: odds ratio; SCOFF: "Sick, Control, One stone, Fat, Food" questionnaire; GCSE: General Certificate of Secondary Education.

Interestingly, eating disorder risk was more frequent in females, students with divorced parents, students who lived alone, students who were seeking a romantic relationship or were married, students who were at post-secondary vocational institute/college (private-public) institutional level and were more likely to have marks under merit level. Also, the means scores for the psychological factors of depression, stress and anxiety were higher in students with eating disorder risk (Table 2).

\subsection{Stepwise Logistic Regression}

A stepwise logistic regression (forward method based on maximum likelihood) [51,52] was conducted to predict the possibility of eating disorders using the factors significantly associated with eating disorder risk from univariate analyses. After four steps, the final model included only four predictors, which were all significant.

A test of the full model against a constant only model was statistically significant, indicating that the predictors as a set reliably distinguished between eating disorder risk and non-eating-disorder risk $\left(\chi^{2}=251.284, \mathrm{df}=8, p<0.0001\right)$. The model as a whole explained between $13.1 \%$ (Cox and Snell $\left.R^{2}\right)$ and $17.7 \%$ (Nagelkerke $R^{2}$ ) of the variance in eating disorders risk and correctly classified $67.8 \%$ of cases. The odds ratios are presented in Table 3. All of the independent variables (in various categories) were significant predictors of eating disorder risk. The model produced depicted that depression, stress, female gender, being married and searching for a romantic relationship were risk factors of having an eating disorder risk. Particularly, female students were 1.60-times more likely than men to be at risk for eating disorders. Also interesting is that married people and people seeking a romantic relationship were 2.53- and 1.64-times more likely to develop a risk for eating disorders. Assessment of interaction terms did not increase the explanatory power of the model, and thus, the main effects are described. 
Table 3. Stepwise logistic regression results.

\begin{tabular}{lccc}
\hline & Odds Ratio & Odds ratio 95\% CI & $\boldsymbol{p}$-Value \\
\hline Depression & 1.82 & $1.60-2.08$ & $<0.0001$ \\
Stress & 1.18 & $1.03-1.34$ & 0.014 \\
Gender & & & \\
Female & 1.60 & $1.30-1.96$ & $<0.0001$ \\
Male [Reference group] & & & \\
Personal Family Status & & & \\
Married & 2.53 & $1.51-4.25$ & $<0.0001$ \\
Divorced & 0.29 & $0.09-0.92$ & 0.036 \\
Permanent relation, but unmarried & 1.03 & $0.75-1.41$ & 0.874 \\
Engaged & 1.44 & $0.77-2.71$ & 0.253 \\
Seeking romantic relationship & 1.64 & $1.14-2.35$ & 0.008 \\
Single [Reference group] & & & \\
Constant & 0.45 & & $<0.0001$ \\
\hline
\end{tabular}

The logistic regression model was evaluated with the Receiver Operating Characteristic (ROC) curve. In this analysis, the power of the model's predicted values to discriminate between positive a negative cases is quantified by the Area under the ROC curve (AUC) [53]. The AUC was satisfactory 0.717 (95\% CI $0.693-0.741$ ) (Figure 1), signifying a satisfactory discriminatory effect between those with eating disorders and those not.

Figure 1. Receiver operating characteristic (ROC) curve examining the discriminatory efficiency of the logistic regression model to detect eating disorder risk.

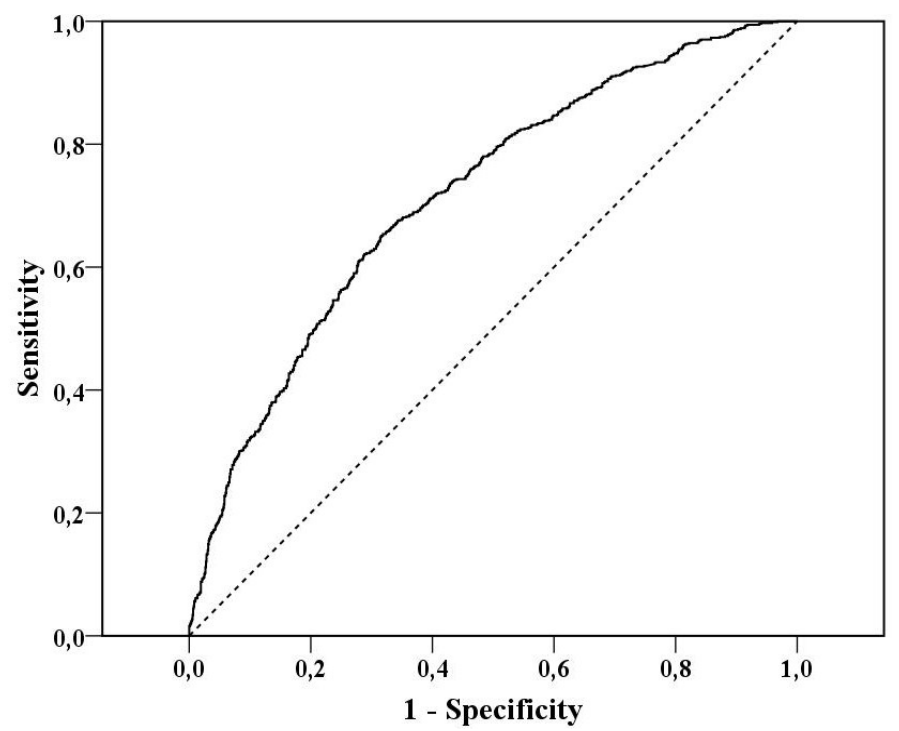

\subsection{Suggested Psychological Model}

The path model presented adequate fit (Root Mean Square Error of Approximation $=0.041$, Comparative Fit Index $\left.=0.847, \chi^{2}=8166.048, \mathrm{df}=1941, p<0.0001\right)$. The paths from debilitating and facilitating anxiety leading to anxiety were significant and explained $65.5 \%$ in the variance of anxiety (Figure 2). The standardized total effects of these two types of test anxiety were positive predictors of 
eating disorders, albeit only weakly $(0.138$ and 0.160$)$ (Table 4$)$. The paths leading to eating disorders risk were all significant at the $10 \%$ level of significance, but only depression showed a highly significant effect (path coefficient $=0.456, p<0.001$ ). This model seems to explain $28.25 \%$ in the variation of eating disorders. Stress was also a moderately positive predictor of eating disorders, but anxiety results are not so conclusive, due to low standardized estimate and non-significant value at the $5 \%$ level of significance.

Figure 2. Path model leading to eating disorders risk. Paths from independent to dependent variables depict standardised estimates and double arrows indicate correlations; $* p<0.001$.

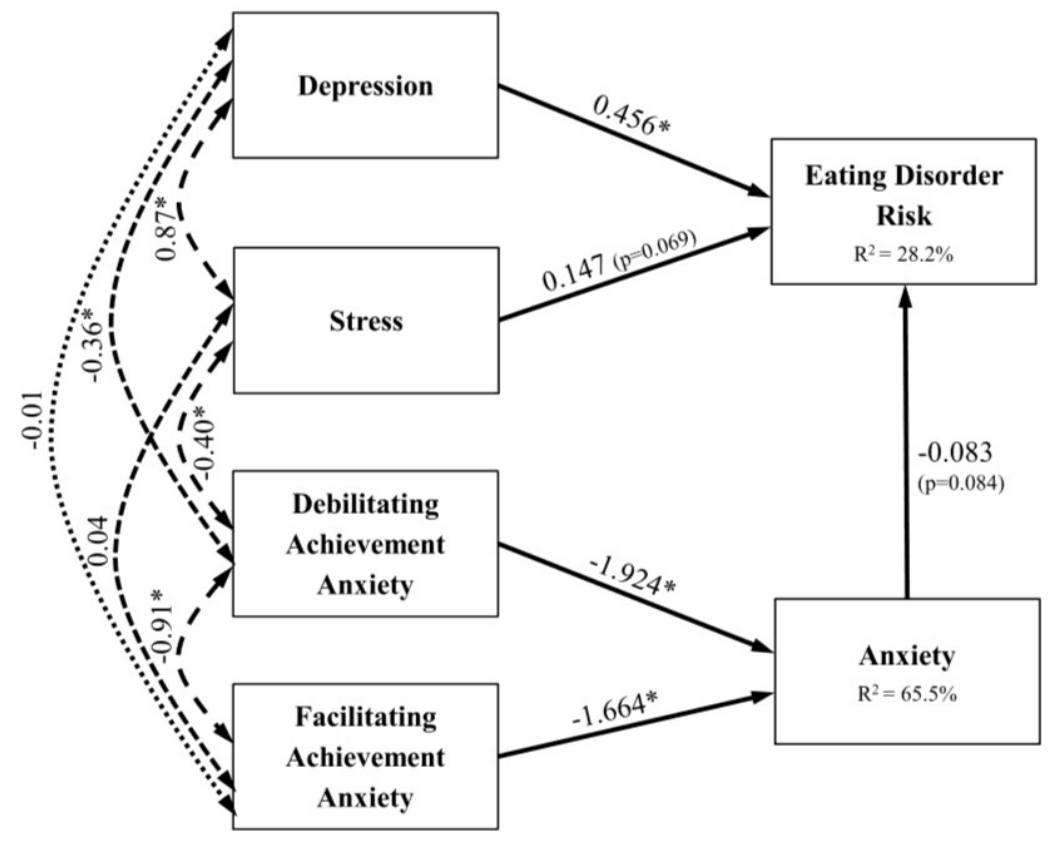

Table 4. Path modelling results.

\begin{tabular}{llcccc}
\hline $\begin{array}{c}\text { Dependent } \\
\text { variable }\end{array}$ & \multicolumn{1}{c}{$\begin{array}{c}\text { Path } \\
\text { precursor }\end{array}$} & $\begin{array}{c}\text { Unstandardised } \\
\text { estimate }\end{array}$ & $\begin{array}{c}\text { Standardised } \\
\text { estimate }\end{array}$ & p-Value & $\boldsymbol{R}^{\mathbf{2}}$ \\
\hline Eating & Depression & 0.212 & 0.456 & $<0.001$ & 0.282 \\
Disorder & Stress & 0.072 & 0.147 & 0.069 & \\
Risk & Anxiety & -0.046 & -0.083 & 0.084 \\
$($ SCOFF $\geq 2)$ & Debilitating Achievement Anxiety & 0.087 & 0.160 & & \\
& Facilitating Achievement Anxiety & 0.131 & 0.138 & & $<0.001$ \\
\hline Anxiety & Debilitating Achievement Anxiety & -1.877 & -1.924 & 0.655 \\
& Facilitating Achievement Anxiety & -2.828 & -1.664 & $<0.001$ & \\
\hline
\end{tabular}

\section{Discussion}

In the present study, we performed an extensive sample survey of students who have finished high-school and are attending higher education or post-secondary vocational institutes. Findings are interesting, since they for the first time pointed out the role of employment status with eating disorder risk. This was not maintained in the multivariate models. Family status was also a strong predictor of 
eating disorder risk, with being married or being in a relationship being strong predictors. Academic sources of anxiety were not retained in the stepwise logistic regression, but played a role in the suggested psychological pathway.

So, how are these results interpreted? The suggested pathway examined with structural equation modelling gives a satisfactory explanation. Academic anxiety explained $65.5 \%$ of anxiety in general. Anxiety in general was higher in subjects with eating disorder risk, but wasn't a significant predictor in the logistic regression model; this, however, should not be considered as negative, since anxiety was highly correlated with stress and depression, which were strong positive predictors of eating disorder risk in both the pathway and the logistic regression model.

Other results showed that being married was considered a strong predictor of risk of eating disorders. We haven't explored relationship quality or marital stress per se to provide an explanation for this finding. However, other studies have done so [19,54]. Kiriike et al. [55] found that $69 \%$ of the Japanese female patients with an eating disorder in their study developed the illness due to marital problems, separation or divorce. These results indicate, as might be expected, that it is marital problems that lie at the heart of the association between marriage and disordered eating. From the present data, the odds ratio for the interaction of stress with being married was 2.98 (95\% CI 0.97-9.18, $p=0.057)$, which was borderline significant; however, it indicates that both variables together increase the risk of eating disorders [56].

The contribution of the present study to eating disorders scholarship is three-fold. It initially gives an image of college health in Greece, where the risk of eating disorders is prevalent in around $40 \%$ of the student population and replicates established findings that eating disorders are associated with female gender and depression/stress. Next, it connects academic activities with the risk of eating disorders, by assessing the impact of achievement anxiety on eating disorder risk. Although academic anxiety was an important component of anxiety in general, it did not affect directly eating disorder risk. Thirdly, married couples and people seeking a romantic relationship were more probable to have a risk of eating disorders; this is possibly explained due to marital or relationship stress.

Nevertheless, the present study has certain limitations. The major limitation is that no diagnostic data was available against which to validate the eating disorders screening. Secondly, the cross-sectional nature of the study can establish arguments against causality between variables, for which a longitudinal approach would be more appropriate to address. Finally, the data was collected only from college students, who represent a portion of the general population. Thus, a study of selecting a larger general population sample will increase generalisability and also the validity of the study.

So, eating disorder risk is prevalent among student populations in Greece. At the moment infrastructures for dealing with these are not present in Greek colleges. Although psychological services are present, they are treated with mistrust, because there is the fear of stigmatization of having a mental disorder $[33,57,58]$. It might prove necessary in the future to screen college freshman with the SCOFF questionnaire upon entry to university. The professional services include health clinics in psychiatric hospitals and certain eating disorder clinics in paediatric hospitals in Greece. These specialised centres need to involve primary care centres (in Greece mainly general physicians - pathologoi) for assessing metabolism parameters that could indicate disordered eating (e.g., albumin, protein, thyroid function tests, plasma cortisol, etc.). Finally, taking into account the effects of eating disorders on physical and emotional health, it is suggested that prevention programs are in need. The effect of the 
mass media on the advent of eating disorders has been discussed extensively [35]. However, campaigns showing the clinical importance of eating disorders, as well as the long term effects on people, should be outlined and be considered necessary. These campaigns will assist in alleviating stigmatization associated with these disorders. Once these infrastructures are in place, the road towards professional therapy will seem more natural and less agonizing.

\section{Conclusions}

The present study is one of the largest in the literature assessing eating disorders risk in non-clinical samples. It presented evidence suggesting that female gender, interpersonal relationships and achievement anxiety have a significant association with eating disorder risk; certain of these associations have been observed for the first time in international literature. These results suggest a need for monitoring eating disorder risk in non-clinical populations by attentively identifying risk factors and for the Greek society specifically, the need for more active prevention measures.

\section{Conflict of Interest}

The authors declare no conflict of interest.

\section{Appendix: Exploratory Factor Analysis of DASS}

The 42 items of DASS were subjected to principal components analysis (PCA) using PASW 18.0. Prior to performing PCA, the suitability of data for factor analysis was assessed. Inspection of the correlation matrix revealed the presence of many coefficients 0.300 and above. The Kaiser-Meyer-Olkin value was 0.976, exceeding the recommended value of $0.600[59,60]$, and Bartlett's Test of Sphericity reached statistical significance [61], supporting the factorability of the correlation matrix.

PCA revealed the presence of four components, with eigenvalues exceeding 1, explaining 37.3\%, $6.1 \%, 3.2 \%$ and $3.0 \%$ of the variance respectively. An inspection of the scree plot revealed a clear break after the third component. Using Cattell's [62] scree test, it was decided to retain three components for further investigation. This was further supported by the results of parallel analysis, which showed only three components, with eigenvalues exceeding the corresponding criterion values for a randomly generated data matrix of the same size (42 variables $\times 1865$ respondents).

The three component solution explained a total of $46.7 \%$ of the variance. To aid in the interpretation of these, three components Oblimin Rotation was performed. This method was preferred, because of the high positive correlations between components (Depression and Anxiety: 0.472; Depression and Stress: 0.622; Anxiety and Stress: 0.506). This component solution is in accordance with the original factor analyses of DASS, producing three components depicting depression, anxiety and stress, but with slight differing in certain items and having to drop two items (Table A1). Thus, factor scores were chosen to depict these latent factors instead of item sums for each component. 
Table A1. Oblimin rotation results of three factor solution of DASS items.

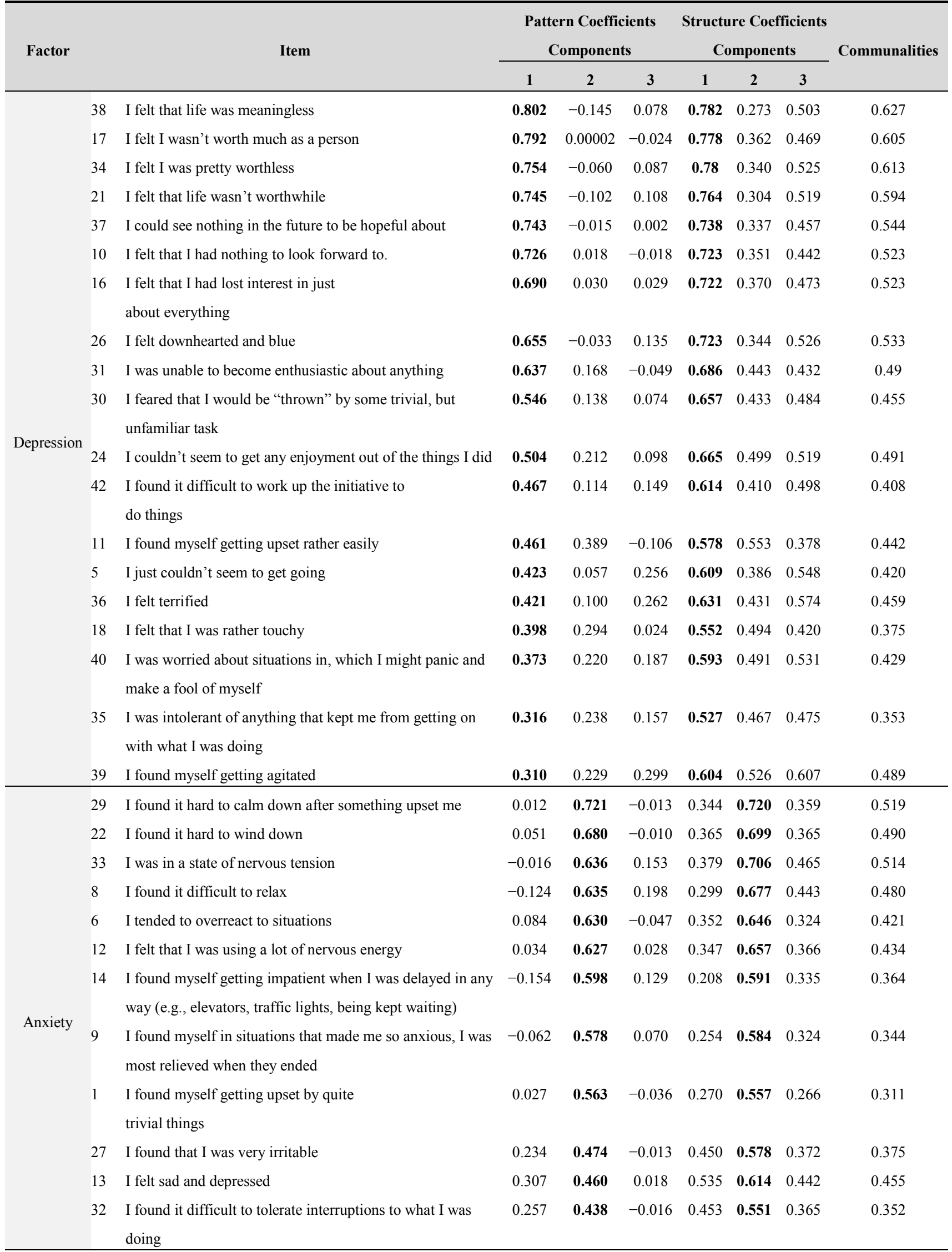


Table A1. Cont.

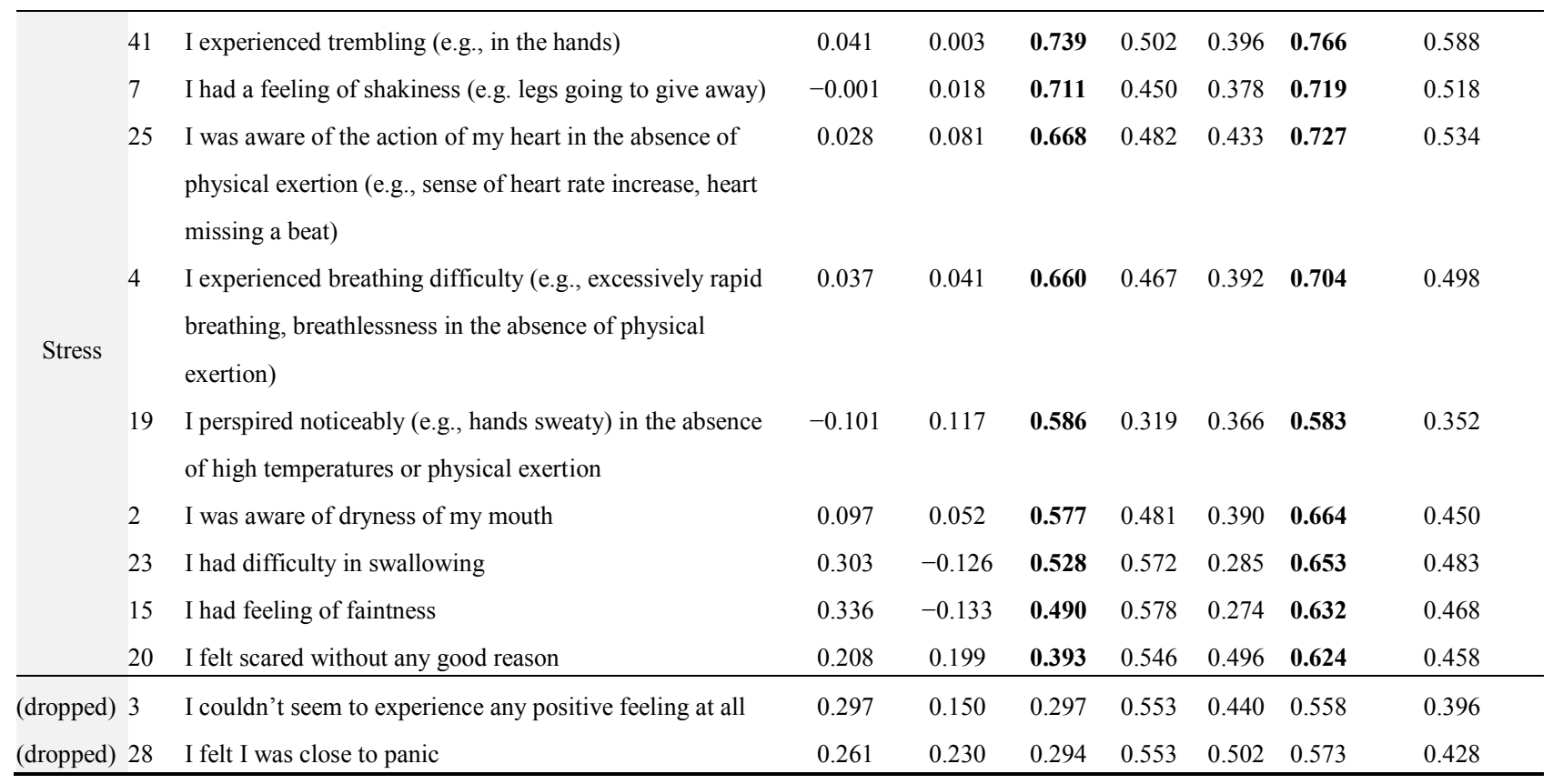

\section{References and Notes}

1. Eisenberg, D.; Nicklett, E.J.; Roeder, K.; Kirz, N.E. Eating disorder symptoms among college students: Prevalence, persistence, correlates, and treatment-seeking. J. Am. Coll. Health 2011, 59, 700-707.

2. Fairburn, C.G. Eating Disorders. In Encyclopedia of Life Sciences; John Wiley \& Sons, Ltd.: Chichester, UK, 2001.

3. Memon, A.; Adil, S.; Siddiqui, E.; Naeem, S.; Ali, S.; Mehmood, K. Eating disorders in medical students of Karachi, Pakistan-A cross-sectional study. BMC Res. Notes 2012, 5, 84.

4. LaCaille, L.J.; Dauner, K.N.; Krambeer, R.J.; Pedersen, J. Psychosocial and environmental determinants of eating behaviors, physical activity, and weight change among college students: A qualitative analysis. J. Am. Coll. Health 2011, 59, 531-538.

5. Piran, N.; Robinson, S.R. Associations between disordered eating behaviors and licit and illicit substance use and abuse in a university sample. Addict. Behav. 2006, 31, 1761-1775.

6. Reyes-Rodríguez, M.L.; Sala, M.; von Holle, A.; Unikel, C.; Bulik, C.M.; Cámara-Fuentes, L.; Suárez-Torres, A. A description of disordered eating behaviors in Latino males. J. Am. Coll. Health 2011, 59, 266-272.

7. Fairburn, C.G.; Cooper, Z.; Shafran, R. Cognitive behaviour therapy for eating disorders: A "transdiagnostic" theory and treatment. Behav. Res. Ther. 2003, 41, 509-528.

8. Kostopoulou, M.; Varsou, E.; Stalikas, A. Thought-Shape Fusion in bulimia nervosa: An experimental investigation. Eat. Weight Disord. 2011, 16, e86-e92.

9. Jacobi, C.; Hayward, C.; de Zwaan, M.; Kraemer, H.C.; Agras, W.S. Coming to terms with risk factors for eating disorders: Application of risk terminology and suggestions for a general taxonomy. Psychol. Bull. 2004, 130, 19-65.

10. Heatherton, T.F.; Nichols, P.; Mahamedi, F.; Keel, P. Body weight, dieting, and eating disorder symptoms among college students, 1982 to 1992. Am. J. Psychiatry 1995, 152, 1623-1629. 
11. Delinsky, S.S.; Wilson, G.T. Weight gain, dietary restraint, and disordered eating in the freshman year of college. Eat. Behav. 2008, 9, 82-90.

12. Striegel-Moore, R.H.; Silberstein, L.R.; Rodin, J. Toward an understanding of risk factors for bulimia. Am. Psychol. 1986, 41, 246-263.

13. Vohs, K.D.; Heatherton, T.F.; Herrin, M. Disordered eating and the transition to college: A prospective study. Int. J. Eat. Disord. 2001, 29, 280-288.

14. Misra, R.; Castillo, L.G. Academic stress among college students: Comparison of American and international students. Int. J. Stress Manag. 2004, 11, 132-148.

15. Franko, D.L.; Jenkins, A.; Roehrig, J.P.; Luce, K.H.; Crowther, J.H.; Rodgers, R.F. Psychometric properties of measures of eating disorder risk in latina college women. Int. J. Eat. Disord. 2012, $45,592-596$.

16. Hoerr, S.L.; Bokram, R.; Lugo, B.; Bivins, T.; Keast, D.R. Risk for disordered eating relates to both gender and ethnicity for college students. J. Am. Coll. Nutr. 2002, 21, 307-314.

17. Steiger, H.; Liquornik, K.; Chapman, J.; Hussain, N. Personality and family disturbances in eating-disorder patients: Comparison of "restricters" and "bingers" to normal controls. Int. J. Eat. Disord. 1991, 10, 501-512.

18. Polivy, J.; Herman, C.P. Causes of eating disorders. Annu. Rev. Psychol. 2002, 53, 187-213.

19. Arcelus, J.; Yates, A.; Whiteley, R. Romantic relationships, clinical and sub-clinical eating disorders: A review of the literature. Sex. Relation. Ther. 2012, 27, 147-161.

20. Fergusson, D.M.; Horwood, L.J.; Lynskey, M.T. The effects of unemployment on psychiatric illness during young adulthood. Psychol. Med. 1997, 27, 371-381.

21. Weich, S.; Lewis, G. Poverty, unemployment, and common mental disorders: Population based cohort study. BMJ 1998, 317, 115-119.

22. Cain, A.S.; Epler, A.J.; Steinley, D.; Sher, K.J. Concerns related to eating, weight, and shape: Typologies and transitions in men during the college years. Int. J. Eat. Disord. 2012, 45, 768-775.

23. Fichter, M.M.; Elton, M.; Sourdi, L.; Weyerer, S.; Koptagel-Ilal, G. Anorexia nervosa in Greek and Turkish adolescents. Eur. Arch. Psychiatry Neurol. Sci. 1988, 237, 200-208.

24. Mildred, H.; Paxton, S.J.; Wertheim, E.H. Risk factors for eating disorders in Greek- and Anglo-Australian adolescent girls. Int. J. Eat. Disord. 1995, 17, 91-96.

25. Yannakoulia, M.; Sitara, M.; Matalas, A.L. Reported eating behavior and attitudes improvement after a nutrition intervention program in a group of young female dancers. Int. J. Sport Nutr. Exerc. Metab. 2002, 12, 24-32.

26. Yannakoulia, M.; Matalas, A.L.; Yiannakouris, N.; Papoutsakis, C.; Passos, M.; Klimis-Zacas, D. Disordered eating attitudes: An emerging health problem among Mediterranean adolescents. Eat. Weight Disord. 2004, 9, 126-133.

27. Fichter, M.M.; Quadflieg, N.; Georgopoulou, E.; Xepapadakos, F.; Fthenakis, E.W. Time trends in eating disturbances in young Greek migrants. Int. J. Eat. Disord. 2005, 38, 310-322.

28. Yannakoulia, M.; Panagiotakos, D.B.; Pitsavos, C.; Tsetsekou, E.; Fappa, E.; Papageorgiou, C.; Stefanadis, C. Eating habits in relations to anxiety symptoms among apparently healthy adults. A pattern analysis from the ATTICA Study. Appetite 2008, 51, 519-525.

29. Costarelli, V.; Demerzi, M.; Stamou, D. Disordered eating attitudes in relation to body image and emotional intelligence in young women. J. Hum. Nutr. Diet. 2009, 22, 239-245. 
30. Gonidakis, F.; Sigala, A.; Varsou, E.; Papadimitriou, G. A study of eating attitudes and related factors in a sample of first-year female Nutrition and Dietetics students of Harokopion University in Athens, Greece. Eat. Weight Disord. 2009, 14, e121-e127.

31. Bilali, A.; Galanis, P.; Velonakis, E.; Katostaras, T. Factors associated with abnormal eating attitudes among Greek adolescents. J. Nutr. Educ. Behav. 2010, 42, 292-298.

32. Koskina, N.; Giovazolias, T. The effect of attachment insecurity in the development of eating disturbances across gender: The role of body dissatisfaction. J. Psychol. 2010, 144, 449-471.

33. Michala, L.; Antsaklis, A. Anorexia nervosa: A psychiatric illness with gynecological manifestations. A survey of knowledge and practice among Greek gynecologists. Eur. J. Obstet. Gynecol. Reprod. Biol. 2010, 153, 170-172.

34. Costarelli, V.; Antonopoulou, K.; Mavrovounioti, C. Psychosocial characteristics in relation to disordered eating attitudes in greek adolescents. Eur. Eat. Disord. Rev. 2011, 19, 322-330.

35. Peroutsi, A.; Gonidakis, F. Eating disorders and mass media. Psychiatrike 2011, 22, 231-239.

36. Konstantakopoulos, G.; Varsou, E.; Dikeos, D.; Ioannidi, N.; Gonidakis, F.; Papadimitriou, G.; Oulis, P. Delusionality of body image beliefs in eating disorders. Psychiatry Res. 2012, 200, 482-488.

37. Bartlett, J.E., II; Kotrlik, J.W.; Higgins, C.C. Organizational research: Determining appropriate sample size in survey research appropriate sample size in survey research. Inf. Technol. Learn. Perform. J. 2001, 19, 43-50.

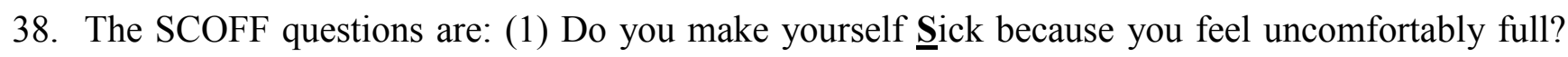

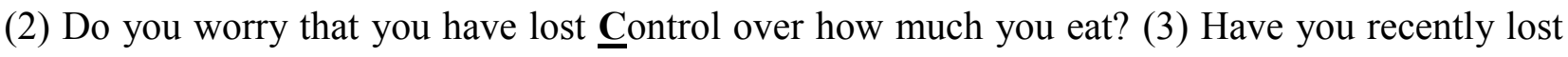

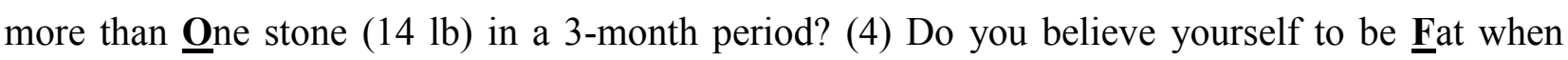
others say you are too thin? (5) Would you say that Food dominates your life?

39. Morgan, J.F.; Reid, F.; Lacey, J.H. The SCOFF questionnaire: Assessment of a new screening tool for eating disorders. BMJ 1999, 319, 1467-1468.

40. Perry, L.; Morgan, J.; Reid, F.; Brunton, J.; O’Brien, A.; Luck, A.; Lacey, H. Screening for symptoms of eating disorders: Reliability of the SCOFF screening tool with written compared to oral delivery. Int. J. Eat. Disord. 2002, 32, 466-472.

41. Fragkos, K.C. Female gender and depression as predictive factors of eating disorders in a sample of Greek university students. Clin. Nutr. Suppl. 2010, 5, 203.

42. Fragkos, K.C.; Frangos, C.C.; Sotiropoulos, I.; Giovanis, A.N.; Tilikidou, I.; Manolopoulos, I. Prevalence and risk factors of eating disorders in Greek undergraduate students. Eur. Psychiatry 2011, 26, 717.

43. Pannocchia, L.; di Fiorino, M.; Giannini, M.; Vanderlinden, J. A psychometric exploration of an italian translation of the SCOFF questionnaire. Eur. Eat. Disord. Rev. 2011, 19, 371-373.

44. Muro-Sans, P.; Amador-Campos, J.A.; Morgan, J.F. The SCOFF-c: Psychometric properties of the Catalan version in a Spanish adolescent sample. J. Psychosom. Res. 2008, 64, 81-86.

45. Lovibond, P.F.; Lovibond, S.H. The structure of negative emotional states: Comparison of the Depression Anxiety Stress Scales (DASS) with the Beck Depression and Anxiety Inventories. Behav. Res. Ther. 1995, 33, 335-343.

46. Edmed, S.; Sullivan, K. Depression, anxiety, and stress as predictors of postconcussion-like symptoms in a non-clinical sample. Psychiatry Res. 2012, 200, 41-45. 
47. Lyrakos, G.N.; Arvaniti, C.; Smyrnioti, M.; Kostopanagiotou, G. Translation and validation study of the depression anxiety stress scale in the greek general population and in a psychiatric patient's sample. Eur. Psychiatry 2011, 26, 1731.

48. Alpert, R.; Haber, R.N. Anxiety in academic achievement situations. J. Abnorm. Soc. Psychol. 1960, 61, 207-215.

49. Kazelskis, R.; Reeves, C.; Kersh, M.E.; Bailey, G.; Cole, K.; Larmon, M.; Hall, L.; Holliday, D.C. Mathematics anxiety and test anxiety: Separate constructs? J. Exp. Educ. 2000, 68, 137-146.

50. Kline, R.B. Principles and Practice of Structural Equation Modeling, 3rd ed.; Guilford Press: New York, NY, USA, 2010.

51. Stepwise logistic regression is designed to find the most parsimonious set of predictors that are most effective in predicting the dependent variable. The process of adding more variables stops when all of the available variables have been included or when it is not possible to make a statistically significant reduction in $-2 \cdot \log$ likelihood using any of the variables not yet included.

52. Menard, S.W. Applied Logistic Regression Analysis; Sage: Thousand Oaks, CA, USA, 2002.

53. The AUC, sometimes referred to as the c-statistic (or concordance index), is a value that varies from 0.5 (discriminating power not better than chance) to 1.0 (perfect discriminating power).

54. Woodside, D.B.; Lackstrom, J.B.; Shekter-Wolfson, L. Marriage in eating disorders Comparisons between patients and spouses and changes over the course of treatment. J. Psychosom. Res. 2000, 49, 165-168.

55. Kiriike, N.; Nagata, T.; Matsunaga, H.; Tobitani, W.; Nishiura, T. Married patients with eating disorders in Japan. Acta Psychiatr. Scand. 1996, 94, 428-432.

56. The odds ratio for this interaction term can be computed with the covariance matrix of the coefficients, as estimated from logistic regression. This can be provided upon request.

57. Madianos, M.G.; Madianou, D.; Vlachonikolis, J.; Stefanis, C.N. Attitudes towards mental illness in the Athens area: Implications for community mental health intervention. Acta Psychiatr. Scand. 1987, 75, 158-165.

58. Papadopoulos, C.; Leavey, G.; Vincent, C. Factors influencing stigma: A comparison of Greek-Cypriot and English attitudes towards mental illness in north London. Soc. Psychiatry Psychiatr. Epidemiol. 2002, 37, 430-434.

59. Kaiser, H. A second generation little jiffy. Psychometrika 1970, 35, 401-415.

60. Kaiser, H. An index of factorial simplicity. Psychometrika 1974, 39, 31-36.

61. Bartlett, M.S. A Note on the Multiplying Factors for Various $\chi^{2}$ Approximations. J. R. Stat. Soc. Series B Stat. Methodol. 1954, 16, 296-298.

62. Cattell, R.B. The scree test for the number of factors. Multivariate Behav. Res. 1966, 1, 245-276.

(C) 2013 by the authors; licensee MDPI, Basel, Switzerland. This article is an open access article distributed under the terms and conditions of the Creative Commons Attribution license (http://creativecommons.org/licenses/by/3.0/). 